\title{
Momentum flux estimates for South Georgia Island mountain waves in the stratosphere observed via satellite
}

\author{
M. Joan Alexander, ${ }^{1}$ Stephen D. Eckermann, ${ }^{2}$ Dave Broutman, ${ }^{3}$ and Jun $\mathrm{Ma}^{3}$ \\ Received 7 April 2009; revised 26 May 2009; accepted 4 June 2009; published 30 June 2009.
}

[1] We show high-resolution satellite observations of mountain wave events in the stratosphere above South Georgia Island in the remote southern Atlantic Ocean and compute the wave momentum fluxes for these events. The fluxes are large, and they imply important drag forces on the circulation. Small island orography is generally neglected in mountain wave parameterizations used in global climate models because limited model resolution treats the grid cell containing the island as ocean rather than land. Our results show that satellite observations can be used to quantitatively constrain mountain wave momentum fluxes, and they suggest that mountain waves from island topography may be an important missing source of drag on the atmospheric circulation. Citation: Alexander, M. J., S. D. Eckermann, D. Broutman, and J. Ma (2009), Momentum flux estimates for South Georgia Island mountain waves in the stratosphere observed via satellite, Geophys. Res. Lett., 36, L12816, doi:10.1029/ 2009 GL038587.

\section{Introduction}

[2] Accurate representation of the stratospheric circulation can have important effects on seasonal to decadal climate forecasts [Shaw and Shepherd, 2008; Deckert and Dameris, 2008], and mountain wave breaking has a strong effect on the circulation at these levels [Palmer et al., 1986; McFarlane, 1987; Eckermann and Preusse, 1999]. Finite computing resources limit spatial resolution in global models, so drag forces from small-scale breaking mountain waves are parameterized. The parameterizations have long been recognized as critical for weather prediction [Palmer et al., 1986; Webster et al., 2003], and now new sensitivities to the drag are reported in climate simulations that incorporate trends in greenhouse gases and ozone-depleting chemicals [Sigmond et al., 2008; Li et al., 2008; McLandress and Shepherd, 2009]. Mountain wave drag parameterizations vary widely among models, and global observational constraints on mountain wave momentum fluxes are needed to reduce uncertainties in these important model projections.

\section{AIRS Observations}

[3] Global constraints can only come from satellite measurements. The Atmospheric Infrared Sounder (AIRS) instrument [Aumann et al., 2003] on NASA's Aqua satellite is

\footnotetext{
${ }^{1}$ Colorado Research Associates Division, NorthWest Research Associates, Boulder, Colorado, USA.

${ }^{2}$ Naval Research Laboratory, Washington, D. C., USA.

${ }^{3}$ Computational Physics, Inc., Springfield, Virginia, USA
}

unique in its sensitivity to wave-like temperature anomalies at high horizontal resolution, sufficient to image waves with horizontal wavelengths longer than $40 \mathrm{~km}$ [Alexander and Barnet, 2007]. Satellite measurements at microwave frequencies have a factor of 3 coarser horizontal sampling [Eckermann et al., 2007]. Previous detection of mountain waves from limb-scanning satellite instruments [Eckermann and Preusse, 1999; Preusse et al., 2002; Alexander et al., 2008 ] observed the wave vertical structure in fine detail, but obtained only relatively coarse sampling of the wave structure in the horizontal. Uncertainties in momentum flux from these previous analyses remain high [Ern et al., 2004; Alexander et al., 2008].

[4] Wing-shaped wave patterns downstream of South Georgia Island $\left(37^{\circ} \mathrm{W}, 54.5^{\circ} \mathrm{S}\right)$ observed by AIRS are shown in Figure 1. South Georgia is a small island about $170 \mathrm{~km}$ long and $30 \mathrm{~km}$ wide located in the remote south Atlantic, roughly $1000 \mathrm{~km}$ to the east-southeast of the Falkland Islands. The highest point on the island is Mount Paget at $2915 \mathrm{~m}$. The colors in Figure 1 represent AIRS brightness temperature anomalies $\left(T^{\prime}\right)$, which are derived from radiances in channel 75 and that show anomalies in emission from $\mathrm{CO}_{2}$ near $40-\mathrm{km}$ altitude in the stratosphere [Alexander and Barnet, 2007].

[5] The ship wave-like patterns in Figure 1 persisted for four days in this event, observed 6-9 September 2003. The patterns somewhat resemble structure seen in low-level clouds downstream of small volcanic islands [Gjevik and Marthinsen, 1978; Gassó, 2008] due to mountain waves trapped within the lowest few kilometers of the atmosphere [Simard and Peltier, 1982; Eckermann et al., 2006]. Are the patterns we observe at $40 \mathrm{~km}$ in the stratosphere similarly caused by trapped waves in a much deeper tropospherestratosphere duct, or are they caused by vertically propagating waves? If they are vertically propagating, they will carry momentum fluxes and may subsequently drive changes in the circulation.

\section{Model Comparison}

[6] To address this question, the mountain wave field over South Georgia Island on 6-9 SEP 2003 was modeled from $0-50 \mathrm{~km}$ altitude using a time-dependent Fourier-ray algorithm [Broutman et al., 2006; Eckermann et al., 2006; Broutman et al., 2009]. Island topography was specified using 30" resolution United States Geological Survey elevation data interpolated to a $2 \times 2 \mathrm{~km}^{2}$ regional grid. Wind and temperature profiles over the island were specified from $0-50 \mathrm{~km}$ for each observation in Figure 1 using the closest six-hourly NASA Global Modeling and Assimilation Office (GMAO) GEOS-4 analyses. Resulting wave solutions were computed at $1 \mathrm{~km}$ vertical intervals. 

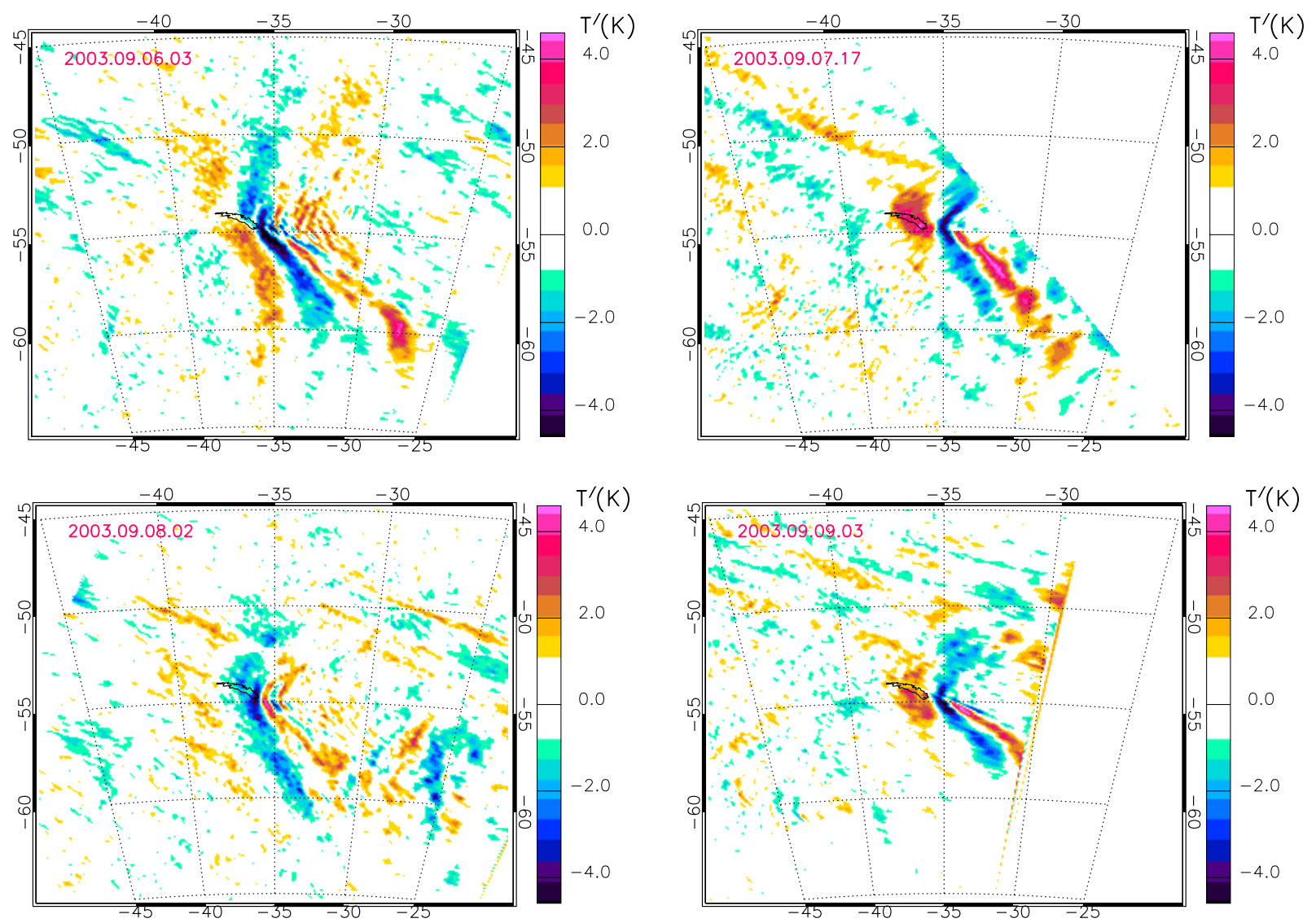

Figure 1. Brightness temperature anomalies $T^{\prime}(\mathrm{K})$ derived from radiances measured in the AIRS $667.78 \mathrm{~cm}^{-1}$ channel that peaks near $40-\mathrm{km}$ altitude. Areas where anomalies are smaller than 3 times the measurement noise [Alexander and Barnet, 2007] appear white. Data in 2003: 6 SEP 0310 UT, 7 SEP 1720 UT, 8 SEP 0300 UT, 9 SEP 0340 UT. (The color scale is saturated at $\pm 4.5 \mathrm{~K}$ for presentation here, but the maximum and minimum values range from -8 to $+7 \mathrm{~K}$.)

[7] Throughout 6-9 SEP 2003, winds over South Georgia were $\sim 20 \mathrm{~m} \mathrm{~s}^{-1}$ at the ground, typically directed northeastward to eastward. Strong persistent eastward shear yielded eastward tropospheric jets of $40-60 \mathrm{~m} \mathrm{~s}^{-1}$ and stratopause jets in excess of $100 \mathrm{~m} \mathrm{~s}^{-1}$ near $40-\mathrm{km}$ altitude. In this environment the model continuously generated mountain waves that propagated rapidly into the upper stratosphere: An example for the 6 SEP 2003 case is plotted in Figure 2. A surface Froude number close to unity suggests the majority of the pressure drag across the island is expected to result in a mountain wave response, as implicitly assumed in the Fourier-ray method. The wave-induced temperature oscillations well reproduce the observed wing-shaped pattern in Figure 1. While the model is capable of simulating wave trapping, the waves in this wing-shaped structure are freely propagating in the vertical from the ground to $40 \mathrm{~km}$. This is in sharp contrast to wing-shaped tropospheric cloud patterns observed downstream of islands, which are produced by
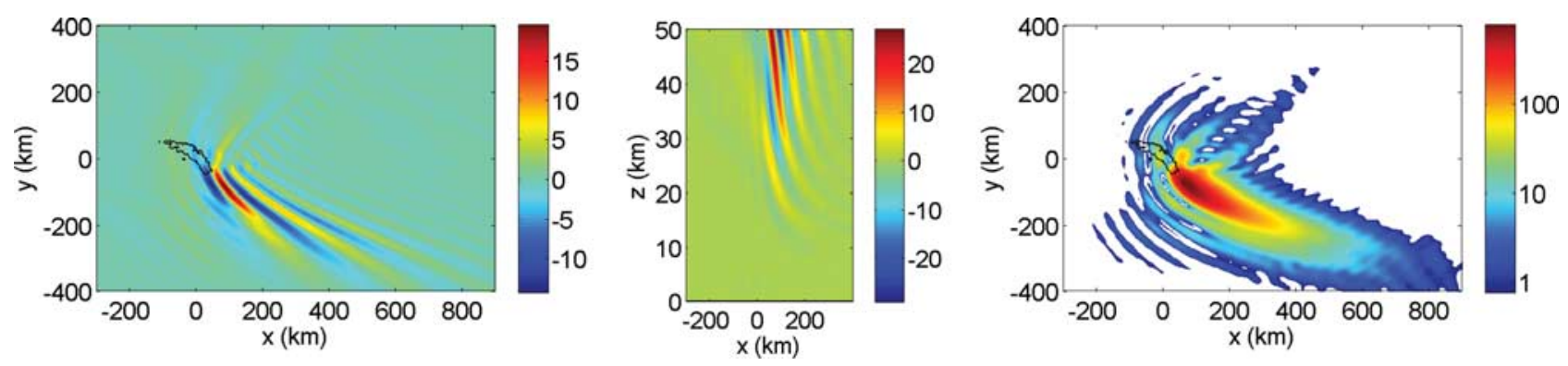

Figure 2. Mountain waves generated by the Fourier-ray model. Only horizontal wavelengths $>40 \mathrm{~km}$ are shown to match the resolution of the observations. (left) Horizontal cross-section of sensible temperature perturbations $T_{a}^{\prime}(\mathrm{K})$ at $40 \mathrm{~km}$ with the island at $\mathrm{x}=\mathrm{y}=0$. (middle) Vertical cross-section of $T_{a}^{\prime}(\mathrm{K})$ at $y=-80 \mathrm{~km}$. (right) Magnitude of the momentum flux vector $(\mathrm{mPa})$ computed from the covariance of horizontal $\left(u^{\prime}, v^{\prime}\right)$ and vertical $\left(w^{\prime}\right)$ wind perturbations $\rho\left|\left(\left\langle u^{\prime} w^{\prime}\right\rangle,\left\langle v^{\prime} w^{\prime}\right\rangle\right)\right|$ at 40-km altitude. 

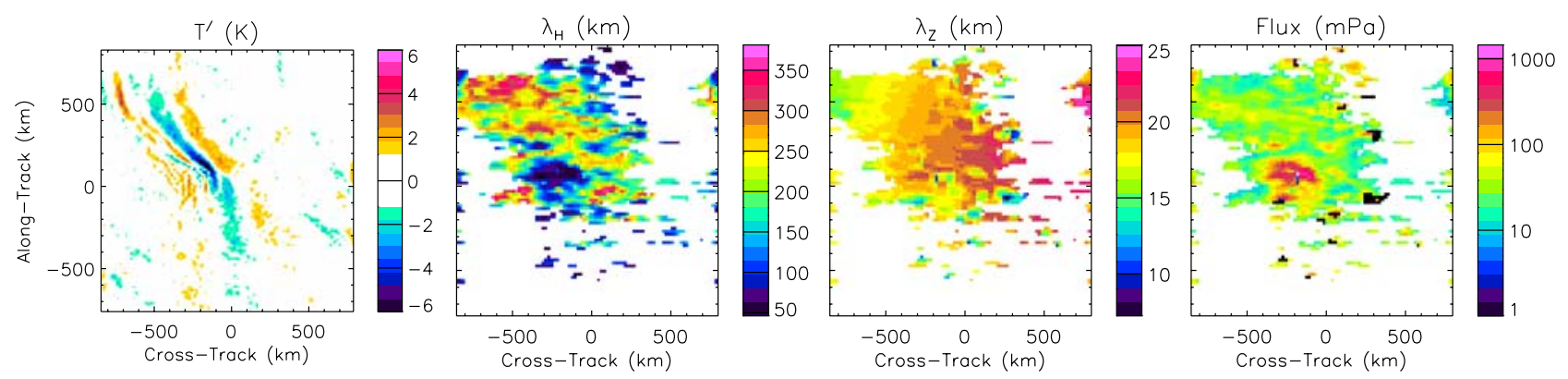

Figure 3. Wave parameters computed for the 6 SEP 2003 overpass plotted in Cartesian coordinates relative to the orbit track, along an angle $154^{\circ}$ from north. North is down and to the right, and S. Georgia Island lies at $(0,0)$. Areas where amplitudes are smaller than 3 times the measurement noise appear white. From left to right: $T^{\prime}, \lambda_{H}, \lambda_{Z}$, and the magnitude of the momentum flux.

trapped waves. This finding permits the use of linear theory for vertically propagating waves in the following analysis of the AIRS observations. The linear theory will allow us to convert satellite brightness temperature amplitudes to true temperature amplitudes for a quantitative comparison to the model result, and for computation of wave momentum flux directly from the observations.

\section{Momentum Fluxes}

[8] To compute momentum flux from the AIRS brightness temperature anomalies, the full three dimensional structure of the wave must be determined [Ern et al., 2004]. Wavelet analysis allows calculation of the spatially resolved brightness temperature amplitude $(\hat{T})$, horizontal wavelength $\left(\lambda_{H}\right)$, and propagation direction of waves in the AIRS data [Alexander and Barnet, 2007]. We derive these properties using the S-transform [Stockwell et al., 1996], and results for the event observed on 6 SEP 0300 UT are shown in Figure 3. Propagation directions, visualized as vectors perpendicular to the lines of constant phase in Figure 1 can only be computed with $180^{\circ}$ ambiguity, however the ambiguity is easily broken with knowledge of the background wind vector and the assumption that mountain waves propagate in the upstream direction against the wind. The flux vector directions therefore vary from northwestward north of the island to southwestward south of the island.

[9] Vertical wavelength is also required for the calculation of momentum flux. To estimate this from the AIRS horizontal cross-sections, we need linear theory and supplementary wind measurements, which we obtain from the GEOS-4 assimilation. The linear dispersion relation,

$$
\lambda_{Z}=2 \pi\left(\frac{N^{2}}{U^{2}}-k_{H}^{2}\right)^{-1 / 2}
$$

relates the vertical wavelength to buoyancy frequency $(N)$, horizontal wavenumber $\left(k_{H}=2 \pi / \lambda_{H}\right)$, and the component of horizontal wind in the direction of wave propagation $(U)$. The wave propagation direction and horizontal wavenumber are determined via the wavelet analysis of the AIRS image [Alexander and Barnet, 2007], and we derive $U$ and $N$ from GEOS-4 analyzed winds and temperatures. The vertical wavelengths computed via equation (1) are also shown in Figure 3.
[10] Brightness temperature anomalies $T^{\prime}$, shown in Figures 1 and 3, were computed from AIRS radiance anomalies approximated as small perturbations via the Planck function [Alexander and Barnet, 2007]. The brightness temperature amplitudes $(\hat{T})$ are attenuated relative to true atmospheric temperature amplitudes because of the deep weighting functions associated with the AIRS channel. Attenuation is strongest for short vertical wavelength waves and weaker for very long vertical wavelength waves. The attenuation factor $A\left(\lambda_{Z}\right)$ varies smoothly from 0 (complete attenuation) at short $\lambda_{Z}$ to 1 (no attenuation) at extreme long $\lambda_{Z}$. For this AIRS channel and for $\lambda_{Z}=20 \pm 5 \mathrm{~km}$ typical of these mountain waves, $A\left(\lambda_{Z}\right)=0.3 \pm 0.1$ [Hoffmann and Alexander, 2009]. The true temperature anomalies $\hat{T}_{a}$ can then be computed as $\hat{T}_{a}=\hat{T} / A\left(\lambda_{Z}\right)$. This gives true temperature amplitudes $\hat{T}_{a}$ of $17 \pm 4 \mathrm{~K}$ averaged over the central region of the wave field, in close agreement with the model result in Figure 2 at 40-km altitude.

[11] With the full three-dimensional structure of the wave event now characterized, we can compute the vector momentum flux at the 40-km altitude level via [Ern et al., 2004],

$$
\left(F_{x}, F_{y}\right)=\frac{1}{2} \rho \frac{(k, l)}{m}\left(\frac{g}{N}\right)^{2}\left(\frac{\hat{T}_{a}}{T}\right)^{2}
$$

where $(k, l)$ is the horizontal wavenumber vector, $m=2 \pi / \lambda_{Z}$, $g=$ gravitational acceleration, and $T, \rho$ are temperature and air density for the large-scale background atmosphere (excluding the waves), here defined by the GEOS-4 analysis.

[12] The absolute value of these fluxes $\left|\left(F_{x}, F_{y}\right)\right|$ shown in Figure 3 reaches very large values $\sim 1000 \mathrm{mPa}$ in the localized region near the center of the wave pattern where the observed horizontal wavelengths are shortest. These fluxes are again very similar to the modelled fluxes shown in Figure 2. For reference, zonal-mean fluxes for small-scale gravity waves are estimated to be $\sim 1-10 \mathrm{mPa}$ in the lower stratosphere [Ern et al., 2004; Alexander et al., 2008]. Note however that meaningful values of momentum flux should be averaged over the horizontal wavelength of the waves, while in Figure 3 we show the fully resolved fluxes at $\sim 20-\mathrm{km}$ resolution. Averaged over a typical global climate model grid scale of $2.5^{\circ} \times 2.5^{\circ}$ downstream of the island gives an average momentum flux of $210 \pm 20 \mathrm{mPa}$, a value five times smaller than the maximum values, but still large compared to zonal means. The comparable average derived 
Table 1. Momentum Fluxes Over South Georgia Island ${ }^{\mathrm{a}}$

\begin{tabular}{ccc}
\hline Date-Time & Max $(\mathrm{mPa})$ & $2.5^{\circ}$ \\
\hline Avg $(\mathrm{mPa})$ \\
09/06/03-03:10 UT & 1400 & 210 \\
09/08/03-17:20 UT & 640 & 80 \\
09/09/03-03:00 UT & 810 & 220 \\
\hline
\end{tabular}

${ }^{\mathrm{a}}$ Local maximum (at $20-\mathrm{km}$ resolution) and $2.5^{\circ} \times 2.5^{\circ}$ averaged.

from the Fourier-ray model is $120 \mathrm{mPa}$. Table 1 lists the momentum fluxes estimated from the four events shown in Figure 1 , both maximum fluxes, and $2.5^{\circ} \times 2.5^{\circ}$ averaged fluxes. Errors estimated as standard deviations about the local means range $\sim 10-20 \%$.

\section{Discussion and Conclusions}

[13] The AIRS observations suggest these mountain waves may occur commonly above South Georgia Island. We examined additional AIRS measurements from July and August when the climatological zonal winds are strong and mountain waves can most easily propagate into the stratosphere for detection in AIRS data. Mountain waves appeared in $16 \%$ of the AIRS overpasses in July and $34 \%$ in August. The AIRS observations therefore suggest that mountain waves from South Georgia propagate to $\sim 40-\mathrm{km}$ altitude commonly in winter.

[14] Above $40 \mathrm{~km}$, the strong eastward winds in the GEOS-4 analysis rapidly weaken to $\sim 0-30 \mathrm{~m} \mathrm{~s}^{-1}$ at $60 \mathrm{~km}$ altitude in the local region above the island during 6-9 SEP 2003. These high-altitude shear reversals are believed to be driven by gravity wave drag. Fourier-ray mountain wave solutions extending up to $60 \mathrm{~km}$ diagnose convectively unstable waves above $\sim 50 \mathrm{~km}$, which will lead to flux dissipation and wave drag. Assuming an arealand time-mean wave flux of $80 \mathrm{mPa}$ (Table 1), if just $10 \%$ of this flux is uniformly dissipated between $50-60 \mathrm{~km}$ altitude, these mountain waves exert a localized drag on the flow of $\sim 200 \mathrm{~m} \mathrm{~s}^{-1}$ day $^{-1}$, more than sufficient to drive the weakened circulation at these altitudes. Comparable surface stresses $(\sim 50-100 \mathrm{mPa})$ occur over southern hemisphere orography in climate model parameterizations [Webster et al., 2003].

[15] From these observational estimates we conclude that South Georgia, and other mountainous small islands, are recurrent significant sources of mountain wave momentum flux and climatologically significant sources of drag on the circulation of the stratosphere and mesosphere. Existing mountain wave drag parameterizations are problematic for isolated islands like South Georgia. At low horizontal resolutions typical of climate models, land-sea masks will generally tag the large grid box encompassing South Georgia as an ocean point, so the island's mountain wave drag would be neither resolved nor parameterized by such a model. In much higher resolution models that can identify the South Georgia grid box as a land point, the mean subgrid-scale orographic variance used by the parameterization will still be very small due to the still large fraction of ocean around the island at the grid box edges, leading to substantial underestimation of the mountain wave flux from the island. Although global weather forecasting models are typically run at much higher horizontal resolution than climate forecast models, isolated island topography could remain a missing or underestimated source of mountain wave momentum flux in global models far into the future.

[16] Coarse resolution global models rely on parameterized mountain wave drag to correct biases in the zonal mean wind and temperature structure at mid- to high-latitudes [Palmer et al., 1986; McFarlane, 1987; Austin et al., 2003]. This has been effective in the northern hemisphere, where there are large continental landmasses and numerous mountain ranges. However wind biases in the models have persisted at southern latitudes. The biases have improved somewhat with increasing resolution, but still remain today [Hamilton, 2008]. The present results suggest there is a need to include mountain wave drag from isolated island topography in the parameterizations. While the southern hemisphere has far fewer continental mountain ranges than the north, small mountainous islands are scattered across the Southern Ocean, many of which appear to regularly launch waves into the winter stratosphere [Wu et al., 2006]. The accumulated deposition of momentum flux from mountain waves generated by these island sources may be an important missing source of mountain wave momentum flux and wave drag in global models.

[17] Acknowledgments. This work was supported by the National Aeronautics and Space Administration under grant NASA NNH08AE43I issued through the Earth System Science Research using Data and Products from Terra, Aqua, and ACRIMSAT Satellites program. Support for DB was provided by the National Science Foundation under grant ATM-0435789.

\section{References}

Alexander, M. J., and C. Barnet (2007), Using satellite observations to constrain gravity wave parameterizations for global models, J. Atmos. Sci., 64, 1652-1665.

Alexander, M. J., et al. (2008), Global estimates of gravity wave momentum flux from High Resolution Dynamics Limb Sounder observations, J. Geophys. Res., 113, D15S18, doi:10.1029/2007JD008807.

Aumann, H. H., et al. (2003), AIRS/AMSU/HSB on the Aqua mission: Design, science objectives, data products, and processing systems, IEEE Trans. Geosci. Remote Sens., 41, 253-264.

Austin, J., et al. (2003), Uncertainties and assessments of chemistry-climate models of the stratosphere, Atmos. Chem. Phys., 3, 1-27.

Broutman, D., J. Ma, S. D. Eckermann, and J. Lindeman (2006), Fourierray modeling of transient trapped lee waves, Mon. Weather Rev., 134, 2849-2856.

Broutman, D., S. D. Eckermann, and J. W. Rottmann (2009), Practical application of two turning-point theory to mountain-wave transmission through a wind jet, J. Atmos. Sci., 66, 481-494.

Deckert, R., and M. Dameris (2008), From ocean to stratosphere, Science, $322,53-55$.

Eckermann, S. D., and P. Preusse (1999), Global measurements of stratospheric mountain waves from space, Science, 286, 1534-1537.

Eckermann, S. D., D. Broutman, J. Ma, and J. Lindeman (2006), Fourierray modeling of short-wavelength trapped lee waves observed in infrared satellite imagery near Jan Mayen, Mon. Weather Rev., 134, 2830-2848.

Eckermann, S. D., J. Ma, D. L. Wu, and D. Broutman (2007), A threedimensional mountain wave imaged in satellite radiance throughout the stratosphere: Evidence of the effects of directional wind shear, $Q$. J.R. Meteorol. Soc., 133, 1959-1975.

Ern, M., P. Preusse, M. J. Alexander, and C. D. Warner (2004), Absolute values of gravity wave momentum flux derived from satellite data, J. Geophys. Res., 109, D20103, doi:10.1029/2004JD004752.

Gassó, S. (2008), Satellite observations of the impact of weak volcanic activity on marine clouds, J. Geophys. Res., 113, D14S19, doi:10.1029/ 2007JD009106.

Gjevik, B., and T. Marthinsen (1978), Three-dimensional lee-wave pattern, Q. J. R. Meteorol. Soc., 104, 947-957.

Hamilton, K. (2008), Numerical Resolution and Modeling of the Global Atmospheric Circulation: A Review of Our Current Understanding and Outstanding Issues, chap. 1, pp. 8-27, Springer, New York.

Hoffmann, L., and M. J. Alexander (2009), Retrieval of stratospheric temperatures from Atmospheric Infrared Sounder radiance measurements for 
gravity wave studies, J. Geophys. Res., 114, D07105, doi:10.1029/ 2008JD011241.

Li, F., J. Austin, and J. Wilson (2008), The strength of the Brewer-Dobson circulation in a changing climate: Coupled chemistry-climate mode simulations, J. Clim., 21, 40-57, doi:10.1175/2007JCLI1663.1.

McFarlane, N. A. (1987), The effect of orographically excited gravity wave drag on the general circulation of the lower stratosphere and troposphere, J. Atmos. Sci., 44, 1775-1800.

McLandress, C., and T. G. Shepherd (2009), Simulated anthropogenic changes in the Brewer-Dobson circulation, including its extension to high latitudes, J. Clim., 22, 1516-1540, doi:10.1175/2008JCLI2679.1.

Palmer, T. N., G. J. Shutts, and R. Swinbank (1986), Alleviation of a systematic westerly bias in general circulation and numerical weather prediction models through an orographic gravity wave drag parameterization, Q. J. R. Meteorol. Soc., 112, 1001-1039.

Preusse, P., A. Dörnbrack, S. D. Eckermann, M. Riese, B. Schaeler, J. T. Bacmeister, D. Broutman, and K. U. Grossmann (2002), Space-based measurements of stratospheric mountain waves by CRISTA: 1. Sensitivity, analysis method, and a case study, J. Geophys. Res., 107(D23), 8178, doi:10.1029/2001JD000699.

Shaw, T. A., and T. G. Shepherd (2008), Atmospheric science: Raising the roof, Nat. Geosci., 1, 12-13.
Sigmond, M., J. F. Scinocca, and P. J. Kushner (2008), Impact of the stratosphere on tropospheric climate change, Geophys. Res. Lett., 35 L12706, doi:10.1029/2008GL033573.

Simard, A., and W. R. Peltier (1982), Ship waves in the lee of isolated topography, J. Atmos. Sci., 39, 587-609.

Stockwell, R. G., L. Mansinha, and R. P. Lowe (1996), Localisation of the complex spectrum: The S-Transform, IEEE Trans. Signal Process., 44, 998- 1001 .

Webster, S., A. R. Brown, D. R. Cameron, and C. P. Jones (2003), Improvements to the representation of orography in the Met Office Unified Model, Q. J. R. Meteorol. Soc., 129, 1989-2010.

Wu, D. L., P. Preusse, S. D. Eckermann, J. H. Jiang, M. de la Torre Juarez, L. Coy, and D. Y. Wang (2006), Remote sounding of atmospheric gravity waves with satellite limb and nadir techniques, Adv. Space Res., 37, $2269-2277$

M. J. Alexander, Colorado Research Associates Division, NorthWest Research Associates, 3380 Mitchell Lane, Boulder, CO 80301, USA. (alexand@cora.nwra.com)

D. Broutman and J. Ma, Computational Physics, Inc., 8001 Braddock Road, Suite 210, Springfield, VA 22151, USA.

S. D. Eckermann, Naval Research Laboratory, 4555 Overlook Avenue, SW, Washington, DC 20375-5320, USA 